Article

\title{
Intentions to Move from Homelessness to Social Inclusion: The Role of Participation Beliefs, Attitudes and Prior Behaviour
}

\author{
Julie Christian ${ }^{1, *}$, Dominic Abrams ${ }^{2}$, David Clapham ${ }^{3}$, Daniella Nayyar ${ }^{1}$ and Joseph Cotler ${ }^{1}$ \\ ${ }^{1}$ School of Psychology, University of Birmingham, Birmingham, B15 2TT, UK; E-Mails: j.n.christian@bham.ac.uk (J.C.), \\ dxn497@student.birmingham.ac.uk (D.N.), jxc338@bham.ac.uk (J.C.) \\ 2 School of Psychology, University of Kent, Canterbury, CT2 7NP, UK; E-Mail: d.abrams@kent.ac.uk \\ ${ }^{3}$ Henley Business School, University of Reading, Reading, RG6 6UD, UK; E-Mail: d.f.clapham@reading.ac.uk \\ * Corresponding author
}

Submitted: 12 April 2016 | Accepted: 8 September 2016 | Published: 20 October 2016

\begin{abstract}
A key aim of homelessness services is not only to ensure that homeless people attain a secure home, but that this is a pathway to wider social inclusion. However, relatively little is known about the psychological elements that are essential for homeless people to engage with these pathways, nor whether these elements combine in ways that are predictable from previous research. In the present work, we examined both demographic and behavioural precursors, and contemporaneous psychological predictors, of a set of 49 homeless men's intentions to engage with a programme to move them toward long-term housing and social inclusion. Contrary to predictions based on subjective utility and rational choice theories, we found that normative pressure and did not directly predict the men's intentions. Instead, we found that intentions were predicted by their attitudes towards the services, and their specific beliefs about the benefits of particular courses of action (efficacy beliefs), and to a more restricted extent their experience (sociodemographics); and in those with high prior service use histories, only participatory beliefs guided future service use intentions. These findings suggest that it is important to focus on intentions as a highly relevant outcome of interventions, because beliefs about interventions can break the link between past behaviour or habitual service use and future service use. Such interventions may be particularly effective if they focus on the evaluative and efficacy-related aspects of behaviour over time and better understand the benefits the men evaluated the services as offering them.
\end{abstract}

\section{Keywords}

attitudes; homelessness; service use; social inclusion

\section{Issue}

This article is part of the issue "Homelessness and Social Inclusion", edited by Isobel Anderson (University of Stirling, UK), Maša Filipovič Hrast (University of Ljubljana, Slovenia) and Joe Finnerty (University College Cork, Ireland).

(C) 2016 by the authors; licensee Cogitatio (Lisbon, Portugal). This article is licensed under a Creative Commons Attribution 4.0 International License (CC BY).

\section{Introduction}

One of the recurring themes in the debate on homelessness in Britain has been the difficult and fractured nature of the pathways out of homelessness and, therefore the move from social exclusion to social inclusion through the acquisition and maintenance of permanent housing. There has been concern that many pathways out of homelessness are characterised by recurring episodes of housing instability and high dropout rates from different forms of intermediary provision, which casts some doubt on the usefulness of existing forms of provision (Anderson, 2010; Clapham, 2005). As background, provision for homeless people in the UK is mainly based on the 'continuum of care' or 'staircase' approach (Johnsen \& Teixeira, 2010) in which homeless people progress from one form of provision to another on the basis of their perceived ability (as assessed by professional staff) to move 
on to the next stage. To reach the final stage of permanent housing, homeless people have to show to professionals that they are able to cope on their own and are 'tenancy ready'. This system creates many barriers and difficulties for many homeless people to overcome in accessing services and moving through the 'continuum of care' that can test their skills, knowledge and determination. Therefore, within this system it is important to know what factors are important in influencing the chances of success.

The difficulties inherent in the 'continuum of care' approach have led to calls for the adoption of the 'housing first' principles. Under the 'housing first' principles and guidance, the provision of adequate permanent housing is the first priority and cornerstone for further social intervention designed to deal with any ongoing health or social problems, or lack of capabilities to cope in mainstream accommodation. The 'housing first' approach requires less of homeless people before they achieve permanent housing. In explaining the difficulties that homeless people face in achieving successful outcomes of permanent housing in the current situation, the housing literature has tended to attribute the failure rates to housing management practices, or the quality of neighbourhoods or the accommodation provided (Pawson \& Munro, 2010; Warnes, Crane, \& Coward, 2013). As such, the focus has been on the physical quality of the houses that homeless people move on to, the support offered through housing management services, and the quality of the neighbourhood in both physical and, particularly social terms.

A different perspective focuses on homeless persons' own experiences and understanding of their situations. Much of this work has focused on interactions with services, because it is a social context that allows us an opportunity to explore the daily experiences of homeless people find themselves in. Thus, there has been growing interest in the impact of social and psychological factors of those using the programmes, seeing them as part of a multi-faceted solution. Such research often focuses on the presence or absence of an appropriate social network or on family cohesion, believing norms to be an important determinant of service use and 'future housing success'. However, the individual homeless persons' perception of their own choices and their own psychological situation has remained somewhat neglected. One example of a factor that has been overlooked is that of homeless people's self-efficacy-their sense of their ability to achieve an intended or desired result outcomes (Bandura, 1997)-could reasonably be expected to bear on their service use behaviours. Discussion of the role of self-efficacy, and other psychological enablers or inhibitors has been sparse in the housing crisis literature (compared with that of more obvious material or familial factors). The limited focus on psychological variables is regrettable given that they provide powerful proximal predictors of social participation-which is to say, it is the way people make sense of their situation, not just the ob- jective situation itself, that helps to explain differences in the way people behave (Schultz \& Oskamp, 1999).

In addition to the lacuna in conceptual and empirical focus on psychological components of service use, there also remains a dearth of systematic evaluation evidence on the impact of support services on fostering social inclusion for homeless people. More needs to be known both about the ways that interventions have impact (both positive and negative), and which aspects best encourage homeless people's desire to make use of services that will help them achieve social participation. The aim of this paper, therefore, is to report and consider evidence that illuminates the potential impact and the role of efficacy and other related psychosocial factors on homeless people's intentions to use services that can increase aimed at aiding their resettlement in longer-term accommodation, and thereby also enhancing their social participation and inclusion. We first provide some theoretical background regarding these psychological variables, then introduce the research itself and statistically test hypotheses about the link between demographic and psychological variables on the one hand, and serviceuse intentions on the other.

\subsection{Efficacy \& Psychosocial Factors Linked to Housing and Services Uptake}

Social inclusion and exclusion is not simply an economic or social structural phenomenon, it is also experienced most powerfully and directly as a psychological phenomenon-in people's daily experiences (see Abrams \& Christian, 2007). Homeless people are confronted by multiple forms of exclusion, but it can be argued that the psychological dimension is critical in forming their intentions and subsequent actions, in part because the interpersonal information provides a working understanding for their experiences of the structurallevel. To address this, researchers have adopted mainstream psychological approaches to explore homeless people's coping strategies, because motivations to seek housing and employment are thought to be rooted in people's expectations and previous personal experiences. Determination to seek housing is also arguably linked to how people perceive events that unfold in the world, and their ability to tackle adverse circumstances. However, only a handful of studies, focusing on personal outcomes, have looked closely at the role of efficacy and interventions for homeless people (Epel, Bandura, \& Zimbardo, 1999; Park \& Kim, 2014), which is surprising given that 'efficacy' is often viewed as synonymous with empowerment and/or wellbeing in the housing and homelessness literatures (see Clapham, Christian, \& Foye, 2016). Within the domain of homelessness, Epel et al. (1999) found, in a population of US homeless people, that those who had been previously employed and who had a higher level of educational achievement also had a more positive future orientation (a higher ability to plan for the future) despite current personal cir- 
cumstances. While it is possible to argue that a number of personal and situation factors may increase or decrease a strong sense of personal efficacy (self-belief), Epel et al. (1999) too suggest that enhanced personal efficacy leads to greater feelings of empowerment over barriers to housing, and ultimately to more sustained house seeking behaviours and, eventually, to social inclusion.

Within the literature, an efficacy style framework has also been applied in conjunction with social identity theory (SIT) and the more general self-categorization perspective (Abrams \& Hogg, 1990; Tajfel \& Turner, 1979), as well as a model of social attitude formation, the Theory of Planned Behaviour (TPB, Ajzen, 1991) to investigate social perceptions, motives, and sense of 'self'. Here, beliefs about the self were not solely task-based, but the factors were rider reaching such as perceived benefits of service use (i.e., attitudes towards service use), the extent to which homeless people perceived they had personal agency over their service interaction (i.e., perceived control), and the 'influence of social and cultural norms' (i.e., identification and normative influence) were explored in populations of homeless people in the UK and the US. In a series of multinational studies, Christian and colleagues (Christian \& Abrams, 2004; Christian \& Armitage, 2002; Christian, Armitage, \& Abrams, 2003; Christian, Clapham, \& Abrams, 2011) conclude that homeless people's social engagement is predicted both by the extent to which they perceive they have 'some control over their service participation', and by the extent to which they feel able to 'identify' with the staff at facilities. Across studies with over 700 homeless participants, increases in their 'perceived control' led to a greater sense of empowerment. Moreover, the influence exerted by social norms on participation behaviour appears to be linked to the stability of homeless people's support networks. Friendship groups (friendships with other homeless people) were less stable than those with support worker groups and therefore the latter were easier to identify with. The findings suggest that there may well be a hierarchy of social relationships in which staff could be seen as more stable social referents, but that this might change over time as circumstances fluctuate (also see Christian \& Abrams, 2003; Snow \& Anderson, 1987). The results suggest that a combination of factors, efficacy as well as normative-based variables, interact with the social context to determine whether people uptake service opportunities (see, Christian \& Abrams, 2004). Unclear, however, is the role of prior behaviour (which could be either previous service use and measures of housing instability) in shaping intentionswith some research supporting a direct link from prior behaviour to intentions, and other studies suggesting no direct links but providing evidence for an intentionsbehaviour relationship-leaving questions about potential impact of this factor within this domain.

In the present work we extend previous research (Christian \& Abrams, 2003, 2004; Christian et al., 2011) by exploring the potentially distinct but additive contribu- tions of efficacy-based beliefs, attitudes, and normative influences (social influence and social identification with friendship groups) in predicting both current and future housing service use. We are also conscious of the complex nature of the circumstances facing homeless people. Therefore, an important contribution of the present work is to disentangle how contemporaneous psychological variables (attitudes, efficacy and so on) relate to future service use intentions after accounting for the individual's context, defined in terms of differences in the length of time that particular individuals have spent with coping with housing instability, as well as their length of residence at the shelter in which they are currently residing. Arguably, both these indices of past behaviour could be a basis of service use 'habits', which may or may not fully explain continuing and intended active engagement with the housing services and their use (i.e., no relationship between prior behaviour and intentions); or alternatively the findings could demonstrate desire to engage on the part of the men and provide evidence of contextual/structural issues which might present barriers to service use (i.e., no relationship between current behaviour and intentions). As such, the present correlational study seeks to understand to what extent psychosocial variables may play a role in enabling people to break free of their situation and past circumstances in determining future service use intentions, an indicator of their eventual pathway to social participation and inclusion.

\section{Method}

\subsection{Selection and Recruitment}

Prior to conducting the study, service facilities were contacted based on information from experts working with the homeless population in Birmingham (also see, Christian \& Abrams, 2003; Toro et al., 1999; Snow \& Anderson, 1987). The main principles for consideration of these facilities were the location and size of the population served, mainly due to the differences in services offered from different sized facilities. The sample of homeless people was drawn from both large and small facilities, because smaller facilities tended to offer either supported housing or floating support to their homeless clients, whereas larger facilities generally provide both services to their clients. It was considered to be important that both forms were taken into account.

Once facilities agreed to take part in the investigation, two approaches were used to recruit homeless people. First, posters providing information about the study were displayed in common areas; and second, members of staff also approached clients and asked whether they might be willing to take part in the research (see, Christian et al., 2003). Similar procedures have been previously used (Akilu, 1992; Christian \& Armitage, 2002; Christian et al., 2011; Toro et al., 1999). Potential participants, asking opting in, were then included in the interview schedule. 


\subsection{Participants}

Forty-six homeless men from Birmingham, England, ranging in age from 21 to 62 years $(M=38.63, S D=11.54)$ took part in the study. They were predominantly: White British (59\%) and single persons (87\%). Additionally, there was almost an equal split for participants between those with employment/academic qualifications (24), versus those without academic/employment qualifications (22). Of these, 27 participants had experience working as labourers or with 'unskilled jobs', while 19 participants reported having skilled employment backgrounds. The profile of the participants reflects the patterns reported in the single homeless literature (Anderson, 1994; Burrows, 1997; Busch-Geertsema, Edgar, O'Sullivan, \& Pleace, 2010; Fitzpatrick, Johnsen, \& White, 2011; Fitzpatrick, Kemp, \& Klinker, 2000). All participants had used services prior to the study, and on average, the participants had spent six months in their current temporary accommodation, residing at the shelter from which they were sampled.

\subsection{Measures}

\subsubsection{Pilot Study}

In accordance with the framework (TPB; Ajzen, 1991; Bandura, 1997; SIT, Abrams \& Hogg, 1987) used to guide the research, a pilot study was conducted prior to main study, pilot interviews were conducted with ten homeless people. The purpose of these was to gather the content for both the interviews, and to determine whether homeless people felt that use of services led to them securing long-term accommodation, thus ensuring the ecological validity. Interviews used open-ended response formats and lasted an average of one hour. The resulting interview measure consisted of the following items:

\section{Behavioural Intentions}

Behavioural intention items were: "I intend to use a housing programme this month", "I am likely to use a housing programme this month", "The chances are that I will use a housing programme this month," (scored 1 = strongly disagree through to $5=$ strongly agree). The mean of the 3 items was taken as a reliable measure of intention to use a housing programme $(\alpha=0.67)$.

\section{Attitude}

Participants were presented with the statement: "Using a housing programme this month would be". Two response options were provided: important/unimportant; positive/negative," on 5-point scales. The mean of the 2 items was taken as a measure of attitude towards the use of a housing programme $(\alpha=0.78)$.

\section{Norms}

Participants were asked if they felt that friends and families influenced their decision to participate in housing programmes. Only referent beliefs were assessed, because in pilot phases of the work, participants were clear that there was not a relationship between referent beliefs and their motivation to comply. For example, "Those who are important to me think that I should use a housing programme this month" (referent belief) (scored $1=$ disagree completely through to $5=$ agree completely). The item was used as a measure of social norms.

\section{Perceived Control}

A single item tapped perceived control: "How much control do you feel you have over your housing and housing searches?" (scored 1 = disagree completely through to $5=$ agree completely).

\section{Efficacy: Participatory Behavioural Beliefs}

Three items were used to measure participants' participatory beliefs. These items clustered around 'attendance', 'meeting with key workers' (support staff), and their role in activities with Local Government to gain housing. The questions focused on assessing whether the participants felt that they had the skills/confidence necessary to engage in these behaviours to meet their housing related goals, or whether they felt that they were unable to do so (i.e., perception of skills needed related to specific tasks required as identified by them). Items were scored 0 (never) to 5 (very often). The mean of the 3 items was used as a measure of efficacy: participatory behavioural beliefs $(\alpha=0.61)$.

\section{Social Identification}

Two items measured social identification. These included statements such as, "In general, the social groups I belong to are an important part of my self-image". Each were scored 1 (disagree completely) to 5 (agree completely). The mean of the 2 items was taken as a measure of identification with a social group $(\alpha=.91)$.

To help to tease apart the nature of the social relationships that might be important for participants, we also asked about the range and numbers of social contacts, friendships and what they found important features of them, and whether they thought social groups were based on location (i.e., "I have friends in Bournemouth; I have a mate in London." Social groups were not categorical in terms of construal around a 'role' as linked to activities, such as political participation or community network, rather they were linked to geographical locations whether all within one city, Birmingham, or in several locations ranging from London to southern regions of England and Wales). Information was gathered using scoring 1 (low end of scale/no contacts) through to 5 (high end of the scale/several contacts). In addition, open ended questions were also thematically coded and assigned categorical values for analysis.

Sociodemographic Characteristics and Prior Service Use Patterns

Causes of homelessness, views of people's ability to over- 
come housing instability in Britain, length of time spent in the current homeless hostel, level of education/type of employment training, age, ethnicity, and marital status were recorded using open-ended questions. Ethnicity and marital status were binary $(0,1)$ coded for the purpose of statistical analyses. Length of time spent homeless, however, was coded in number of days spent homeless.

\subsubsection{Procedures and Administration}

\section{Administration of Structured Interview}

Consistent with procedures outlined in the literature, homeless people were approached at tables in facilities, or they were randomly selected from daily registers (Toro et al., 1999; also see, Christian et al., 2011). All participants were told that their responses would be kept confidential, and that their assistance would not affect their future opportunities to take part in the services programmes. Prior to taking part in the interviews, homeless people were asked if they would be willing to take part in a series of interactions and told that these meetings would include an interview and intervention classes. If potential participants agreed, then they were provided with more information about the study and a first interview was arranged. Interview schedules were administered verbally and on a one-to-one basis in a quiet area within service facilities. This widely accepted procedure minimizes the effects of literacy on responding (Toro \& Wall, 1991). Interviews took approximately 45 minutes to complete.

\section{Measure of Current Behaviour}

To capture an 'objective measure' of current service use behaviour, service providers were contacted eight weeks after the interviews had been completed. They were asked whether each of the men was still residing at the hostel. A binary coding system was employed and participants were assigned ' 0 ' if they were not still residing at the hostel (because they had moved into other accommodation (longer term)), and ' 1 ' if they were still in residence. (This measure was used in conjunction with prior service use histories and length of time spent without permanent accommodation.)

\section{Results}

\subsection{Preliminary Findings}

It may be surprising given the barriers that homeless people face in the 'continuum of care' approach that, in general, homeless people had positive views of services, and they also felt that most people facing housing issues within British society overcome these difficulties $(M=4.36$ overcome housing difficulties on a 5-point scale). Moreover, they indicated that they did not spend 'a lot' of time worrying about their access to housing ( $M=1.39$ level of worry on a 5-point scale). They men felt that they had 'average' amounts of control over their lives generally ( $M=3.5$ on a 5-point scale) in spite of their circumstances. On the whole, they reported fairly positive views towards (their) housing instability and its resolution, with their concerns largely focused on the process and not access to housing. These themes are reflected in the correlations presented (see below).

\subsubsection{Are Perceived Benefits of Services Hindering Inclusion?}

In this study, we sought to explore perceptions of service utilisation. The overall pattern emerging demonstrates that attitudes, participatory behaviours and norms are interrelated, indicating that the homeless men are primarily motivated by what they perceived the benefits and outcomes of their service utilisation to be (see Tables 1 and 2, which provides correlations amongst the variables). Interestingly, for those still residing at the hostels in which they were interviewed $(n=29$; still residing after interview), there was a strong relationship between homeless people's attitudes and their intentions to continue participation, such that the more benefits that they saw as coming from taking part in housing services, the more likely they were to intend to take part in them. Also consistent with our expectations, intentions to use housing services were associated with a stronger perceived control over one's circumstances $(r=.42, p=.004)$. Participants also felt that they would benefit most from an intervention programme, as tapped by asking them about whether they would find further services to supplement current service to be helpful in their acquisition of permanent accommodation, if they could see the benefits of the service they were using $(r=.417, p=.008)$.

As we have pointed out, perceived benefits of their service use (attitudes), future service use intentions, perceived control, and participatory beliefs were all interrelated, supporting the theory approaches informing the work. In Table 2, we used the average length of stay/contact with the current service as a way to divide (median split procedure) the sample into low and high service use categories to explore differences in future service use intentions. (Although the sample sizes are not equal, the distribution of high and low members across services is, which is why there are no mean differences found amongst locations). For those in the low prior service use category (i.e., 90 days maximum), there is a relationship between prior use and future service use intentions, with those having had the shortest histories of contact with services being those people forming the strongest intentions. More robust future use intentions were also associated with shorter lengths of time spent without permanent accommodation. Other factors correlated with higher future use intentions were age and ethnicity-meaning that younger men, of British Caucasian origin, reported having stronger intentions for future use. This is, in contrast, to those who had longer periods of contact with services (excess of 90 days and up 
Table 1. Descriptive statistics and intercorrelations $(n=46)$.

\begin{tabular}{|c|c|c|c|c|c|c|c|c|c|c|c|c|c|}
\hline & Mean & SD & 1 & 2 & 3 & 4 & 5 & 6 & 7 & 8 & 9 & 10 & 11 \\
\hline 1. $\mathrm{BI}$ & 4.39 & 0.99 & & & & & & & & & & & \\
\hline 2. ATT & 3.97 & 1.21 & $.403 * *$ & & & & & & & & & & \\
\hline 3. SN & 2.11 & 1.69 & .205 & $.367^{*}$ & & & & & & & & & \\
\hline 4. $\mathrm{PBB}$ & 3.44 & 1.62 & $.420 * *$ & .163 & .073 & & & & & & & & \\
\hline 5. Control & 3.52 & 1.56 & .170 & .054 & .007 & .037 & & & & & & & \\
\hline 6. SI & 3.03 & 1.64 & .189 & $.317^{*}$ & .017 & .117 & .067 & & & & & & \\
\hline 7. $\mathrm{Ml}$ & 1.89 & 0.88 & -.78 & $-.351^{*}$ & -.007 & -.149 & -.153 & -.122 & & & & & \\
\hline 8. Current Use & 0.83 & 0.38 & -.165 & .157 & -.084 & -.031 & -.179 & .045 & -.124 & & & & \\
\hline 9. Prior Behaviour & 192.11 & 284.49 & -.260 & -.147 & -.145 & -.058 & $-.321^{*}$ & -.196 & -.069 & .158 & & & \\
\hline 10. Time Homeless & 1652.59 & 2067.07 & .053 & .029 & .054 & -.026 & .084 & .020 & -.062 & .078 & .220 & & \\
\hline 11. Age & 38.63 & 11.54 & -.248 & .046 & -.120 & -.183 & .041 & -.102 & -.242 & .106 & .211 & $.355^{*}$ & \\
\hline 12. Ethnicity & $59 \%$ white & & $.358^{*}$ & .089 & -.068 & .163 & .055 & .099 & -.054 & -.035 & -.022 & .014 & $-.310 *$ \\
\hline
\end{tabular}

Notes: ${ }^{*} p<.05 ;{ }^{* *} p<.01 ; 1 . \mathrm{BI}=$ Behavioural Intentions; 2 . ATT = Attitudes; 3. SN = Subjective Norms; 4. PBB = Participatory Behavioural Beliefs; 5. Control = Perceived Control; 6. SI = Social Identity; 7. MI = Number of Social Groups Reporting Being a Member of; 8. Current Use = moved on or still residing in hostel; 9. PB = length of time spent residing at current hostel (in days); 10. Length of time spent as homeless (reported in days).

to 3 years). Within this population of men, attitudes and intentions are almost synonymous $(r=.849, p=.001)$, showing the close link between perceived benefits and future intentions. Also, there were negative relationships between attitudes and social norms, as well as between time spent without permanent accommodation and perceived benefits of services (i.e., with their attitudes). In these cases, longer spells of homelessness reduced the number benefits viewed as linked with housing services and fewer benefits were associated with more social pressures to engage in service use.

\subsubsection{Is Service Use Behaviour a 'Habit': The Role of Prior Behaviour?}

Turning attention to the absence of a significant correlation between the men's current behaviour and future service use intentions, while inconsistent with what we might expect (see Armitage \& Connor, 2001; Christian et al., 2011), the moderate relationship between prior behaviour and future use intentions means that there is still quite good capacity for predicting what people are likely to do. For this reason, we explore the prediction of intention from a number of variables identified through the correlation analysis, and we test our prognostication using a multiple regression analysis. With future service use intentions as the dependent variable, on Step 1, we entered ethnicity and prior behaviour (length of time spend at without permanent accommodation) to control for the effects of personal experiences amongst the men and the influence this might have on shaping their future use. Then, on Step 2 we entered attitudes and participatory behaviours. In this way, we can test the relative contributions of each of these psychosocial variables, and the extent to which these outweigh the influ- ence of personal habits, or circumstances (i.e., length of time), or background (ethnicity) in forming future service use intentions.

The regression analysis (see Table 3 ) showed that prior behaviour (length of time homeless) and ethnicity explained $12.6 \%$ of the variance, $F_{\text {change }}(2,42)=3.02$, $p=.059$, with a significant effect for ethnicity. (This allows us to control for the impact of any influence from prior behaviours before exploring the contributions of other background variables. Once these are examined we move to examine the impact of psychosocial variables). The addition of attitude and participatory behavioural beliefs accounted for a further $24 \%$ of the variance, $F_{\text {change }}(2,40)=7.55, p<.005$, so that the model as a whole accounted for $36.5 \%$. Overall, the findings suggest that prior and current experiences were much less important in shaping intentions, with emphasis instead given to attitudes, perceived benefits and to a lesser extent to the men's ethnicities ${ }^{1}$.

Given the relationship between future use intentions and prior use, we also conducted the regression analysis using the responses of those in the lower service use population $^{2}$. Variables were entered in the same ordering as described above.

The regression analysis (see Table 4) showed that prior behaviour (length of time homeless) and ethnicity explained $27.6 \%$ of the variance, $\mathrm{F}_{\text {change }}(2,29)=5.52, p=$ .009 , with a significant effect for both factors. The addition of attitude and participatory behavioural beliefs accounted for a further $14.4 \%$ of the variance, $F_{\text {change }}(2,27)$ $=3.363, p<.05$, so that the model as a whole accounted for $42 \%$. Overall, the findings suggest that the homeless experiences and ethnicity were much less important in shaping future use intentions ( $p=.068$ and .062 respectively), with emphasis on participatory beliefs $(p=.02)$.

\footnotetext{
${ }_{1}^{1}$ If we treat ethnicity as a random factor rather than as a measured variable, then $p=$ n.s.

${ }^{2}$ With an $n$-size of 33 , we have power at .95 (with the effect size).
} 


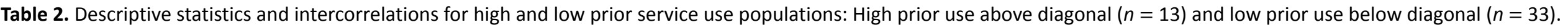

\begin{tabular}{|c|c|c|c|c|c|c|c|c|c|c|c|c|c|c|}
\hline & Mean & SD & 1 & 2 & 3 & 4 & 5 & 6 & 7 & 8 & 9 & 10 & 11 & 12 \\
\hline 1. $\mathrm{BI}$ & $4.38(4.40)$ & $1.02(.98)$ & - & $.849 * *$ & -0.457 & 0.273 & .535 & 0.216 & -0.46 & -0.18 & 0.03 & 0.517 & 0.086 & 0.255 \\
\hline 2. ATT & $3.08(4.03)$ & $1.12(1.25)$ & 0.245 & - & $-.669 *$ & 0.092 & .548 & 0.231 & -0.443 & -0.184 & -0.038 & $.595^{*}$ & -0.029 & 0.152 \\
\hline 3. SN & $2.00(2.15)$ & $1.07(1.71)$ & -0.106 & -0.352 & - & -0.023 & .000 & -0.167 & 0 & 0.191 & 0.286 & -0.153 & 0.068 & 0.371 \\
\hline 4. PBB & $3.61(3.36)$ & $1.49(1.68)$ & $.474 * *$ & 0.193 & -0.393 & - & .134 & -0.116 & -0.149 & 0.391 & 0.124 & -0.276 & 0.039 & 0.045 \\
\hline 5. Control & $3.60(3.48)$ & $1.55(1.58)$ & .031 & -.118 & .038 & -.314 & - & .259 & $-.803^{*}$ & .312 & .045 & .420 & .162 & .008 \\
\hline 6. SI & $2.00(3.04)$ & $1.75(1.61)$ & 0.178 & $.351^{*}$ & 0.487 & 0.204 & -.009 & - & -0.261 & 0.342 & -0.183 & 0.117 & -0.4 & 0.469 \\
\hline 7. $\mathrm{MI}$ & $2.00(1.84)$ & $1.00(.83)$ & 0.102 & -0.308 & 0.11 & -0.16 & .128 & -0.053 & - & -0.096 & 0.067 & -0.532 & -0.378 & -0.165 \\
\hline 8. Current Use & $92 \%$ & $78.8 \%$ & -0.166 & 0.259 & 0.004 & -0.14 & -.314 & -0.032 & -0.300 & - & 0.219 & -0.343 & 0.165 & -0.228 \\
\hline 9. Prior Behaviour & 176 days & 231 days & $-.360 *$ & -0.172 & 0.065 & -0.12 & $-.445^{*}$ & -0.201 & -0.133 & 0.131 & - & 0.058 & 0.121 & 0.101 \\
\hline 10. Time Homeless & 500 days & 445 days & $-.372 *$ & -0.178 & 0.183 & -0.134 & -.440 & 0.006 & 0.09 & -0.001 & $.696 * *$ & - & 0.235 & -0.07 \\
\hline 11. Age & 36 years & 43 years & $-.384 *$ & 0.107 & 0.135 & -0.295 & -.015 & 0.013 & -0.236 & 0.039 & 0.431 & 0.281 & - & -0.433 \\
\hline 12. Ethnicity & $61 \%$ White-British & 54\% White-British & $.400 *$ & 0.074 & 0.032 & 0.201 & .070 & -0.053 & -0.009 & 0.005 & -0.407 & -0.017 & -0.299 & - \\
\hline
\end{tabular}

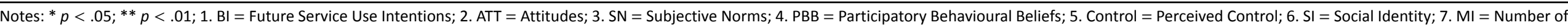
Social Groups Reporting Being a Member of; 8 . Current Use = moved on or still residing in hostel; 9. PB = length of time spent residing at current hostel (in days); 10 . Length of time spent as homeless (reported in days). 
Table 3. Hierarchical multiple regression analysis predicting future service use intentions.

\begin{tabular}{|c|c|c|c|c|c|c|c|}
\hline \multicolumn{2}{|c|}{ Step/Predictor } & \multirow{3}{*}{$\frac{\mathrm{R}}{.355}$} & \multirow{3}{*}{$\begin{array}{l}\mathrm{R}^{2} \\
.126\end{array}$} & \multirow{3}{*}{$\begin{array}{l}F_{\text {Change }} \\
3.022\end{array}$} & \multirow{3}{*}{$\frac{d f_{a}}{2,42}$} & \multirow{3}{*}{$\begin{array}{l}\text { B } \\
695^{*} \\
-2.464\end{array}$} & \multirow{3}{*}{$\begin{array}{l}\text { SE } \\
.287 \\
.000\end{array}$} \\
\hline 1. & Ethnicity & & & & & & \\
\hline & Length of Time Spent Homeless & & & & & & \\
\hline \multirow[t]{4}{*}{2.} & Ethnicity & .605 & .365 & 7.554 & 2,40 & $.529 *$ & .254 \\
\hline & Length of Time Spent Homeless & & & & & -2.525 & .000 \\
\hline & Attitude & & & & & $.266^{*}$ & .105 \\
\hline & Participatory Behavioural Beliefs & & & & & $.198^{*}$ & .078 \\
\hline
\end{tabular}

Notes: Dependent measure: future service use intention; * $p<.05$.

Table 4. Hierarchical multiple regression analysis predicting future service use intentions ( $n=33$; low prior service use included).

\begin{tabular}{|c|c|c|c|c|c|c|c|}
\hline \multicolumn{2}{|c|}{ Step/Predictor } & \multirow{3}{*}{$\begin{array}{l}\mathrm{R} \\
.525\end{array}$} & \multirow{3}{*}{$\begin{array}{l}\mathrm{R}^{2} \\
.276\end{array}$} & \multirow{3}{*}{$\frac{\mathrm{F}_{\text {Change }}}{5.52^{* *}}$} & \multirow{3}{*}{$\frac{d f_{a}}{2,29}$} & \multirow{3}{*}{$\begin{array}{l}\mathrm{B} \\
362^{*} \\
-2.22^{*}\end{array}$} & \multirow{3}{*}{$\begin{array}{l}\text { SE } \\
.313 \\
.000\end{array}$} \\
\hline 1. & Ethnicity & & & & & & \\
\hline & Length of Time Spent Homeless & & & & & & \\
\hline \multirow[t]{4}{*}{2.} & Ethnicity & .648 & .420 & 3.363 & $2,27^{*}$ & .286 & .296 \\
\hline & Length of Time Spent Homeless & & & & & -1.95 & .000 \\
\hline & Attitude & & & & & .675 & .089 \\
\hline & Participatory Behavioural Beliefs & & & & & $2.35^{*}$ & .089 \\
\hline
\end{tabular}

Notes: Dependent measure: future service use intention; ${ }^{*} p<.05 ;{ }^{* *} p<.01$.

\section{Discussion}

The general point emerging from these findings is that effective services need to understand and target the whole person, but that there may be important time periods to understand when and how people are willing to form intentions and to use services aimed at aiding them. In this study, based on an application of theory of planned behaviour (Ajzen, 1991) and efficacy principles (Bandura, 1997), the homeless men suggest that they have identified of skills or behaviours that might overcome the perceived barriers to reaching longer-term accommodation (participatory behaviours), but they also identify and deal with the presence of potential structural systems/organizational issues that could be inhibiting satisfactory housing outcomes and perpetuate the cycle of social exclusion (absence of a link between intentions and current behaviour). Here, we note the complexity of service use and homeless people's lives. Additionally, picking up on the latter we examine the prior behaviourcurrent behaviour-intention relationship. However, we explore possible patterns of those using services versus those who have moved on. The results of this highlight that barriers to housing might not be the same barriers or hurdles that impact decisions whether to take part in services; the barriers might be very different. The perceptions of different barriers have implication for whether the men were able to form intentions and to sense of efficacy over the tasks that might be relevant to them participating in their own rehousing processes. Then, we show that use of housing services is not a habitual act on the part of homeless people, because there a change in the frequency of behaviour (current behaviour is guided by a cost benefit analysis in which the men actively gauged the benefits of participation (also see Christian \& Abrams, 2003).

To better understand this point about engagement and predicting future service use intentions, let's examine the role of participatory behavioural beliefs (Bandura, 1997). First, the evidence suggests that homeless people's understanding of the phases needed to gain permanent accommodation, and their assessment of whether they possess the skills required to successfully complete the tasks/steps, together are key elements in their intentions about whether to try to advance their situation to gain permanent accommodation. Similarly, the perceived benefits (Ajzen, 1991) of the delivery of the service use were important. The more positively they evaluated the service delivery (higher attitude scores), the more likely they were to report positive participatory beliefs, showing the close link between content and delivery in determining future use (service use intentions) (Eagly \& Chaiken, 1993). While the data are only cross sectional, they map on to other longitudinal data, which also showed that determinants of initial service use were not the same determinants reported after 12 months of engagement (Christian et al., 2003).

Breaking this pattern down in terms of thinking about the process, it is possible that two things could be happening. The first, and most likely, is that perceptions of the use of services and what is needed to overcome barriers to continued participation are not the same, and should not be conceptualized of as such. These barriers could be contextual (and thus the absence of a link with current behaviour) and tie into the local housing environment. But, there might also be a combination of con- 
textual factors and personal resource issues that go on here too (and hence the reason why length of time without accommodation is not related but rather length of engagement with service). Therefore, it might be seeing two populations for the following reasons: homeless people with more positive attitudes to services might stay or development other links within the services, and those with more negative attitudes might move-on, because the resources needed might not be gleaned through engagement but by benefits and resources in achieving satisfactory housing outcomes. In other words, if those desiring to 'move on' perceive more benefits as drawn from outside of the service, they could see more opportunities laying elsewhere than those men who are more content with the service. That is, the experience of homeless people not using services, but achieving positive housing outcomes, might need to be captured and incorporated in intervention programmes' design in order to facilitate understanding of this. A second possibility is that the men's 'perceived service requirements/needs' are not static but dynamic and change over time, and indeed the potential benefits may also change over time, and therefore this should be considered by those designing and monitoring service delivery (this might also be why longer contact with services decreases intentions for future use. It is possible that needs are being met through other avenues and resources whether personal network or structural in nature and not the service. The flip side is that if the services are aiming for this, then the decrease in future intentions should be recorded positively as an achieved goal).

In the debate about the relative merits of the 'continuum of care' and 'housing first' models, the findings show the importance of psychological variables in enabling homeless people to overcome the many hurdles placed in their way to achieving permanent housing. The fewer the hurdles, the more likely it is that homeless people will have the necessary skills, knowledge and determination to overcome them. Also, the early reward of permanent housing in the 'housing first' approach is more likely to be reflected in more positive evaluations of service outcomes and so increase the intention to participate in programmes, both factors that proved important in determining outcomes in the present study.

As well as the practical and policy implications, there are a number of important theoretical contributions. Bentler and Speckart (1981) and Bagozzi (1981) have suggested that the best predictor for future behaviour is past behaviour, highlighting the central role that prior behaviour is likely to play in guiding choices, actions, and motives of people. This contrasts strongly with Ajzen's (1991) argument that effects of prior behaviour should be absorbed in the attitude, subjective norm, and perceived behavioural control components within the Theory of Planned Behaviour. Prior behaviour should therefore not exert an independent influence on behaviour or future behaviour. Here, however, we would argue that current behaviour might be restrained by social structures, so the reason we are not seeing a direct link is not because the men are not intending to engage, but because there are barriers that are beyond what they perceive. (We indicate that they are beyond their perceptions, because findings suggest that they feel they have knowledge to help in the resettlement process.) What is interesting is that prior behaviour appears to have an optimal window for facilitating task-related efficacy and intentions for future service use. Shorter and more intensive contact seems to be more effective for active engagement, whereas longer sustained periods of contact change the pattern associated with intentions and cost/benefit analysis carried out by the men. Importantly, this does not seem to be connected to the length of time spent without permanent accommodation Given that these services rely on a co-creation model, it highlights that homeless people see their needs, and contributions, as important in charting the directions in which help might be developedincluding the notion that these might not be static but more dynamic in nature.

One unexpected finding in this study was that we did not observe a strong role of norms or identification with intentions or behaviours. This differs from our prior work (Christian \& Armitage, 2002; Christian et al., 2011) and that of others (Snow \& Anderson, 1987). One factor that maps onto this difference is that the present context is housing whereas previous work focused on outreach services. It is possible that housing intentions have a more individualistic focus - ultimately concerned with the person's own personal situation. The present evidence suggests that if norms and identity have an influence on intentions it may be rather indirect. For example, norms were related to attitudes but not directly to intentions. In contrast, it seems likely that use of outreach services involves a focus on provision that is often shared with others such as food, other material or emotional supports and so forth. Therefore, the role of norms and identity may be more proximal to the behaviour given the immediacy of the context. However, further research, and ideally longitudinal evidence, is needed to understand how and when group identity and shared social norms may be implicated in housing intentions.

This highlights some interesting methodological points and constraints on the application of our findings. The current study provides a concrete step towards understanding more about the relationship between psychosocial variables and future service use, but it does not shed light on when those perceived benefits are likely to change (relationship between attitudes and current and prior behaviour), or why there is a disparity between current behaviour with prior behaviour to that of future use. The complexities of this would likewise have to be unpacked using more qualitative and narrative forms of data collection. Additionally, we realize that this is a restricted sample size and that we have not include women's views. It is likely in another location and with a mixed gender sample we would find some variations in the patterns. But equally such an application would 
answer important questions about the influence of the structural context. It is possible that locations such as London, for example, will follow the same emergence of routines between services, either because members of staff move between organizations, or because the framework and participation in professional networks shapes the provision that is offer. Suffice to say that such application would be a welcome-and would be an important contribution.

The present findings suggest that focusing on homeless people's evaluations of their prospects and choices, and their beliefs about the effectiveness of pursuing various options for action can play an important role in their developing effective intentions. This does not, of course, mean that they will be able to overcome the very real material and practical barriers to inclusion and finding housing that undoubtedly exist, but at least it does mean that some of the psychological obstacles may be overcome and homeless people could be enabled to persist more with action that is likely to be effective. In turn, we know that things that increase social inclusion also increase well-being, and feed into a virtuous cycle that helps to build social capital and other important non-financial resources (Abrams \& Christian, 2007; Abrams, Hogg, \& Marques, 2005). In summary, the present research offers an optimistic prospect for those planning interventions that can support homeless people. The past is not an inevitable portent of the future and the right kind of support does seem to hold the potential for helping homeless people to perceive and aim for better outcomes.

\section{Acknowledgements}

We would like to thank Mr. Damien Neadle for his assistance in the preparation of this piece; and Shemeica Thomas, Leyla Williams, Tracey Beech, Amanda Yaffe, and Sara Hussey for their assistance with data collection. We are especially grateful to all of the men and facilities taking part in this study-thank you! And, finally, we would like to express our gratitude to the EPSRC for funding to the first author (EP/P002021/1).

\section{Conflict of Interests}

The authors declare no conflict of interests.

\section{References}

Abrams, D., \& Christian, J. (2007). A relational analysis of social exclusion. In Multidisciplinary handbook of social exclusion research (pp. 211-232). Chichester: John Wiley \& Sons.

Abrams, D., \& Hogg, M. A. (1987). Language attitudes, frames of reference, and social identity: A Scottish dimension. Journal of Language and Social Psychology, 6(3/4), 201-213.

Abrams, D. E., \& Hogg, M. A. (1990). Social identity theory: Constructive and critical advances. Berlin:
Springer-Verlag Publishing.

Abrams, D., Hogg, M. A., \& Marques, J. M. (2005). A social psychological framework for understanding social inclusion and exclusion. In D. Abrams, J. M. Marques, \& M. A. Hogg (Eds.), The social psychology of inclusion and exclusion (pp. 1-26). London: Psychology Press.

Ajzen, I. (1991). The theory of planned behaviour. Organizational Behaviour and Human Decision Processes, 50(2), 179-211.

Akilu, F. (1992). Multi-method approach to the study of homelessness. In P. Kennett (Ed.), New approaches to homelessness (Working Paper 104). Bristol: SAUS Publications.

Anderson, I. (1994). Access to housing for low income single people: A review of recent research and current policy issues. York: The Centre for Housing Policy, University of York.

Anderson, I. (2010). Services for homeless people in Europe: Supporting pathways out of homelessness. In E. O'Sullivan, V. Busch-Geertsema, D. Quilgars, \& N. Pleace (Eds.), Homelessness research in Europe. Festschrift for Bill Edgar and Joe Doherty (pp. 41-63). Brussels: FEANTSA.

Armitage, C. J., \& Conner, M. (2001). Efficacy of the theory of planned behaviour: A meta-analytic review. British Journal of Social Psychology, 40(4), 471-499.

Bagozzi, R. P. (1981). Attitudes, intentions, and behaviour: A test of some key hypotheses. Journal of Personality and Social Psychology, 41(4), 607.

Bandura, A. (1997). Self-efficacy: Toward a unifying theory of behavioural change. Psychological Review, 84(2), 191-215.

Bentler, P. M., \& Speckart, G. (1981). Attitudes "cause" behaviours: A structural equation analysis. Journal of Personality and Social Psychology, 40(2), 226.

Burrows, R. (1997). The social distribution of the experience of homelessness. In R. Burrows, N. Pleace, \& D. Quilgars (Eds.), Homelessness and social policy (pp. 50-68). London: Routledge.

Busch-Geertsema, V., Edgar, W., O'Sullivan, E., \& Pleace, N. (2010). Homelessness and homeless policies in Europe: Lessons from research. In Conference on homelessness (Vol. 9, p. 10).

Christian, J., \& Abrams, D. (2003). The effects of social identification, norms and attitudes on use of outreach services by homeless people. Journal of Community \& Applied Social Psychology, 13(2), 138-157.

Christian, J., \& Abrams, D. (2004). A tale of two cities: Predicting homeless people's uptake of outreach programs in London and New York. Basic and Applied Social Psychology, 26(2/3), 169-182.

Christian, J., \& Armitage, C.J. (2002). Attitudes and intentions of homeless persons towards service provision in South Wales. British Journal of Social Psychology, 41, 219-231.

Christian, J., Armitage, C. J., \& Abrams, D. (2003). Predicting uptake of housing services: The role of selfcategorization in the theory of planned behaviour. 
Current Psychology, 22(3), 206-217.

Christian, J., Clapham, D., \& Abrams, D. (2011). Exploring homeless people's use of outreach services: Applying a social psychological perspective. Housing Studies, 26(5), 681-699.

Clapham, D. F. (2005). The meaning of housing: A pathways approach. London: Policy Press.

Clapham. D. F., Christian, J., \& Foye. C. (2016). The concept of well-being in housing research. Paper presented at the European Network for Housing Research Conference: Governance, Territory and Housing, Belfast.

Eagly, A. H., \& Chaiken, S. (1993). The psychology of attitudes. San Diego, CA: Harcourt Brace Jovanovich College Publishers.

Epel, E. S., Bandura, A., \& Zimbardo, P. G. (1999). Escaping homelessness: The influences of self-efficacy and time perspective on coping with homelessness. Journal of Applied Social Psychology, 29(3), 575-596.

Fitzpatrick, S., Johnsen, S., \& White, M. (2011). Multiple exclusion homelessness in the UK: Key patterns and intersections. Social Policy and Society, 10(4), 501512.

Fitzpatrick, S., Kemp, P., \& Klinker, S. (2000). Single homelessness: An overview of research in Britain. York: Joseph Rowntree Foundation.

Johnsen, S., \& Teixeira, L. (2010). Staircases, elevators and cycles of change: 'Housing First' and other housing models for homeless people with complex support needs. Crisis: London.
Park, S. I., \& Kim, S. (2014). Mediating Effect of selfefficacy in the relationship between anger and functional health of homeless men. Journal of Korean Academy of Nursing, 44(4).

Pawson, H., \& Munro, M. (2010). Explaining tenancy sustainment rates in British social rented housing: The roles of management, vulnerability and choice. Urban Studies, 47(1), 145-168.

Schultz, P. W., \& Oskamp, S. (1999). Social psychology applied perspectives. US Imports \& PHIPEs.

Snow, D. A., \& Anderson, L. (1987). Identity work among the homeless: The verbal construction and avowal of personal identities. American Journal of Sociology, 92, 1336-1371.

Tajfel, H., \& Turner, J. C. (1979). An integrative theory of intergroup conflict. The Social Psychology of Intergroup Relations, 33(47), 74.

Toro, P. A., \& Wall, D. D. (1991). Research on homeless persons: Diagnostic comparisons and practice implications. Professional Psychology: Research and Practice, 22(6), 479.

Toro, P. A., Wolfe, S. M., Bellavia, C. W., Thomas, D. M., Rowland, L. L., Daeschler, C. V., \& McCaskill, P. A. (1999). Obtaining representative samples of homeless persons: A two-city study. Journal of Community Psychology, 27, 157-177.

Warnes, A. M., Crane, M., \& Coward, S. E. (2013). Factors that influence the outcomes of single homeless people's rehousing. Housing Studies, 28(5), 782-798.

\section{About the Authors}
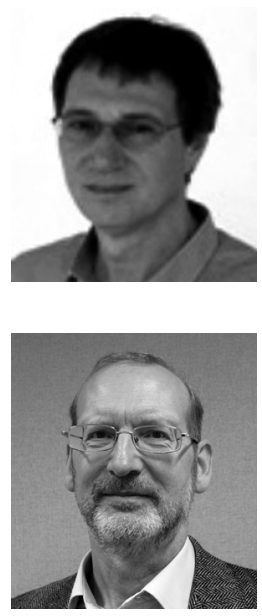

Julie Christian is a Lecturer in Social Psychology. She has worked in both housing and psychology departments, holding Fellowships at London School of Economics and Political Science and at Cardiff University, before being appointment at Birmingham. Julie has an established track record in researching attitudes, social identity, housing and homelessness. She was an Associate Editor for the Journal of Community and Applied Social Psychology. And, as an extension of her research, she holds executive board positions.

Dominic Abrams is Professor of Social Psychology and the Director of the Centre for Group Processes at the University of Kent, Canterbury. A Chartered Psychologist, he is a Fellow of SPSSI, SPSP, and the UK Academy of Social Sciences. He is co-founding editor of the journal Group Processes and Intergroup Relations. He has published extensively in the areas of social identity theory and intergroup relations, particularly working on the relationship between social inclusion and social identity.

David Clapham is Professor of Planning at the University of Reading in the UK. He is the author of Accommodating Difference and The Meaning of Housing published by Policy Press in 2015 and 2005 respectively. He was editor of the journal Housing, Theory and Society for 10 years up to 2015. 


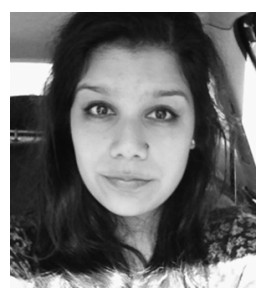

Daniella Nayyar achieved her Bachelor's degree in Human Psychology from the School of Life and Health Sciences at Aston University in 2013. She is currently working towards her Ph.D. exploring environmental and individual differences in performance and learning.

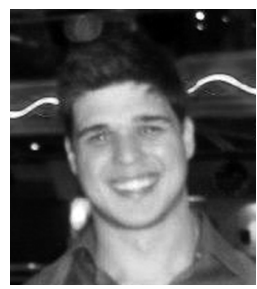

Joseph Cotler holds both Bachelor and Masters degrees, and is currently a Ph.D. candidate in Social Psychology at the University of Birmingham. His work examines differences in social identification amongst multiple group types and subsequent outcome behaviours. 